\title{
RELATOS DE ADOPCIONES MONOPARENTALES: TENSIONES Y POTENCIALIDADES
}

\author{
Mariela Pena \\ Universidad de Buenos Aires \\ Facultad de Filosofía y Letras \\ Instituto Interdisciplinario de Estudios de Género / CONICET
}

\section{RESUMEN}

Aquí exploramos los modos de construir el parentesco por parte de las mujeres que adoptan en Buenos Aires como familias monoparentales. Estas reflexiones se desprenden de una investigación de mayor alcance, en la cual hemos observado frecuentemente en las parejas heterosexuales la presencia de sentidos que refuerzan la pertenencia del adoptado al nuevo grupo, sin desafiar el modelo tradicional de sustitución de familias. Sin embargo, durante el trabajo de entrevistas con mujeres que deciden adoptar independientemente de la conformación de pareja, hallamos que se les suelen otorgar niños de mayor edad, con vínculos afectivos más presentes. Planteamos que dadas estas circunstancias - a veces no deseadas-, las adopciones monoparentales, si bien no representan un modelo alternativo, pueden auspiciar construcciones más flexibles e inclusivas.

\section{PALABRAS CLAVE}

Parentesco, Familia, Maternidad, Adopción monoparental, Relato

\section{ABSTRACT}

We explore the processes to create kinship bonds made by women who adopt in Buenos Aires as single parents. These considerations stem from a broader research, in which we have frequently observed among heterosexual couples meanings and values that intend to reinforce the belonging of the adopted to the new kinship group, without challenging the traditional model of family substitution. However, during the work of interviews with women who have decided to adopt regardless of couple 
formation, we find that they are often granted older children with more present affective ties. We argue that given these circumstances, sometimes unwanted, single parent adoptions, although not representing an alternative model, may propitiate more flexible and inclusive kinship connections.

\section{KEY WORDS}

Kinship, Family, Maternity, Single adoption, Stories 


\section{INTRODUCCIÓN}

Este trabajo reúne elaboraciones que han formado parte de un estudio más amplio, de perspectiva antropológica, en torno a las prácticas y sentidos asignados a las adopciones en el contexto argentino actual. ${ }^{1}$ En dicha investigación, realizada y concluida entre los años 2010 y 2015, indagamos en los significados construidos tanto desde ámbitos estatales como por parte de las diferentes conformaciones familiares que adoptan o desean adoptar niños o niñas.

Con estos propósitos, hemos enmarcado nuestra investigación en la línea de los estudios antropológicos sobre el parentesco, tomando en cuenta los cuestionamientos a la naturalidad de la familia ocurridos a partir de la década de 1970 (Schneider, 1984) y las perspectivas teóricas feministas que también han problematizado esta cuestión (véase Collier, Rosaldo y Yanagisako, 1982). Fundamentalmente, partimos de la idea de que los/as sujetos/as actúan a modo de bricoleurs (Bestard Camps, 2004) en la creación de sus relaciones, integrando creativamente distintos aspectos biológicos y culturales para determinar sus conexiones entre sí. Asimismo, recuperamos el concepto de kinning o emparentamiento (Howell, 2001) — más específico para nuestra problemáticaque nos permite dar cuenta de los procesos mediante los cuales las familias adoptivas expresan sus relaciones en un lenguaje de parentesco.

1 El estudio ha sido volcado en una tesis doctoral en antropología titulada "La adopción de niños y niñas en Buenos aires desde un enfoque etnográfico. Valores y sentidos asignados al parentesco", que ha sido defendida en abril de 2015 en la Facultad de Filosofía y Letras de la Universidad de Buenos Aires.
Partiendo de estos avances, hemos indagado en las representaciones y prácticas a través de las cuales las familias adoptivas cotidianamente crean sus vínculos familiares e incorporan a los niños y niñas adoptados a su propio grupo de parentesco. En un artículo reciente (Pena, 2015), hemos volcado parte de estas reflexiones, en las cuales hemos observado que los matrimonios heterosexuales - pensados como la norma entre las familias adoptivas - frecuentemente expresan nociones que refuerzan la pertenencia exclusiva (Modell, 1994) del adoptado al nuevo grupo de parentesco, en similitud con otros estudios etnográficos (Howell y Marre, 2006; Fonseca, 2011). Allí sostenemos que en nuestro contexto se presenta entre estas familias una clara intención de legitimar y de dar veracidad a las conexiones entre ellos y sus hijos o hijas, en construcciones que procuran respetar una noción particular de verdad. Hallamos que esta concepción, por lo general, se corresponde con diferentes tipos de información respecto al origen, pero desde ella se entiende que dichos vínculos están terminados.

A este respecto, nuestro objetivo aquí consiste en indagar en estos mismos procesos para el caso de conformaciones familiares que resultan alternativas, al tratarse de mujeres que adoptan individualmente, o también denominadas familias monoparentales.

Partiendo de nuestro trabajo de campo previo, hemos observado que si bien deben atravesar procedimientos administrativos y jurídicos idénticos a aquellos que pasan las parejas que adoptan de manera conjunta, ocurre que por lo general se les otorgan niños o adolescentes de mayor edad, con vínculos afectivos más presentes y/o que recuerdan o desean visitar a sus familias. 
Aquí, a modo de hipótesis, sugerimos que al mismo tiempo que dichas circunstancias son vivenciadas de forma discriminatoria, consisten en interesantes grietas frente al modelo tradicional de pensar las adopciones. Hemos observado que en los relatos de las madres emergen, a raíz de situaciones “atípicas", construcciones de los vínculos de parentesco más inclusivas respecto a las vivencias y los afectos previos de los niños adoptados.

Para organizar esta presentación, en el siguiente apartado esbozaremos las cuestiones relativas a la metodología utilizada, dando cuenta de la construcción de un marco propio. Partimos del método etnográfico, pero a su vez combinamos influencias propias de otras corrientes epistemológicas que nos han permitido aproximarnos a dichas experiencias desde la idea de relato. A continuación, detallamos brevemente aspectos que consideramos clave sobre el campo investigativo más general y los conceptos teóricos centrales en los cuales nos hemos apoyado. Luego, nos abocamos al desarrollo de nuestra aproximación empírica al problema, mediante dos relatos de madres adoptivas que tomamos como casos paradigmáticos. Por último, finalizamos presentando las conclusiones a las cuales hemos arribado.

\section{CONSIDERACIONES METODOLÓGICAS}

Como mencionamos en la introducción, las reflexiones que han dado lugar a este artículo han sido construidas en el marco de un trabajo antropológico sobre la conformación de vínculos de parentesco en familias de Argentina en el contexto contemporáneo. De este modo, el enfoque metodológico general se ha basado principalmente en la tradición de las etnografías (Menéndez, 2002; Guber, 2011). Esto ha incluido en el diseño tanto entrevistas en profundidad, abiertas y semi-estructuradas (Oxman, 1998) como observaciones participantes (Hammersley y Atkinson, 1994), ${ }^{2}$ encuentros y conversaciones informales en espacios de reunión de los diferentes actores que nos ocupaban.

En este marco se han realizado, durante las diferentes instancias de la investigación (20102014), un conjunto de 50 entrevistas que han sido planteadas y también luego reagrupadas en función de diferentes interrogantes teóricos. Algunas de ellas, por ejemplo, se han destinado a postulantes a adopción inscriptos formalmente durante los últimos diez años, mientras que otras se han dedicado a parejas heterosexuales que ya han adoptado. Por otra parte, algunas más se han focalizado en parejas del mismo sexo o en la categoría de maternidad y por lo tanto se han dirigido exclusivamente a mujeres. Las personas entrevistadas han sido contactadas a partir de redes personales o profesionales y del método de "bola de nieve", utilizando el propio trabajo de campo y diferentes medios informáticos como insumos para difundir nuestro interés y establecer nuevos contactos (Pena, 2015a, 2015b).

El recorte se ha determinado a partir de que todos/as los entrevistados/as han tenido experiencias con el proceso de la adopción legal

\footnotetext{
2 Siguiendo a Hammersley y Atkinson (1994), este método de investigación social se caracteriza por el objetivo de conocer la manera en que la gente otorga sentido a su cotidianeidad, modelando así los procesos sociales de los que forma parte. Sus técnicas principales consisten en observar, escuchar y preguntar, utilizando todo tipo de datos y fuentes de información para lograr una mejor comprensión de los temas que se van delineando en el transcurso de la práctica, y tomando en cuenta la situación etnográfica en su totalidad.
} 
en la Argentina durante la última década, y residen en la Ciudad de Buenos Aires o en el Conurbano Bonaerense, perteneciendo en prácticamente la totalidad de los casos a los sectores medios urbanos y en una franja etaria promedio entre los 40 y 50 años. A diferencia de los estudios cuantitativos, la cantidad de entrevistas no ha sido definida a priori sino que se ha seguido el criterio de saturación de la información: "el corte significativo se da en el punto de saturación que por supuesto es necesario sobrepasarlo para asegurarse la validez de las conclusiones" (Bertaux, 1999: 7).

Sin embargo, en este recorrido, al adentrarnos en el trabajo con los sentidos propios de las familias adoptivas -y particularmente con las experiencias de las mujeres en torno a su maternidad - hemos requerido ampliar los recursos metodológicos, haciendo uso de otras líneas de abordajes que consideramos complementarias.

En este punto, por un lado, han sido fundamentales las reflexiones epistemológicas feministas que han defendido la aplicación creativa de diferentes técnicas: etnografía, análisis del discurso, métodos cuantitativos, historia oral, biografías, narrativa personal, historiografía, etcétera, con el fin de incorporar aspectos sesgados por la ciencia tradicional y de desvelar su carácter androcéntrico (Fonow y Cook, 2005). Así, este trabajo se ubica en una línea de investigaciones feministas que son diseñadas a partir de aproximaciones multimetodológicas, pero que confluyen en el acuerdo de retomar la experiencia de las mujeres como recurso empírico y teórico (Castañeda Salgado, 2008).
Más allá de los extensos debates que se han desarrollado en torno a esta categoría de “experiencia” y de su representación, ${ }^{3}$ aquí retomamos la premisa planteada por Harding (1998) de comenzar por la vida de las mujeres para identificar en qué condiciones se necesita investigación y qué es lo que puede ser útil que se interrogue de esas situaciones. Asimismo, siguiendo a Castañeda Salgado (2008), hacemos referencia con esta noción a la incardinación de la desigualdad en los cuerpos y las vidas de las mujeres, y a la conformación de experiencias vitales siempre significadas por el poder.

A partir de este conjunto de lineamientos, hemos tomado algunas decisiones metodológicas para el armado del presente trabajo. En primer lugar, de la totalidad de las entrevistas realizadas en el marco de la investigación más amplia se han agrupado aquellas correspondientes a mujeres que han decidido adoptar en forma individual, las cuales conforman un total de 14 entrevistas en profundidad. Como mencionamos anteriormente, las características de las mujeres entrevistadas se encuentran incluidas en aquellas descriptas para el conjunto general, lo cual nos ha permitido establecer particularidades que se deprenden del tipo de conformación familiar y no de otras circunstancias como podría ser el entorno sociocultural o la procedencia geográfica. Luego, este grupo de conversaciones se ha revisado y contrastado con aquellas pertenecientes a otras configuraciones (especialmente matrimonios heterosexuales) buscando similitudes y tensiones o puntos de disrupción.

3 Véase por ejemplo Carmé Adán (2006). 
En segundo lugar, del conjunto de las entrevistas realizadas a madres adoptivas monoparentales, se han seleccionado dos relatos en función de su representatividad, disponibilidad y de sus posibilidades expresivas, establecidas cualitativamente a partir de la interpretación de la investigadora. Para ello se han buscado regularidades, contextualizando lo obtenido mediante estos relatos con nuestra experiencia más extendida en el campo (Pujadas, 2000).

Así, en este artículo nos detendremos extensamente en dos casos de maternidades adoptivas monoparentales que proponemos como paradigmáticos del argumento que pretendemos desarrollar, destinando una considerable atención a la transcripción literal de fragmentos de sus relatos, claramente editados por la investigadora.

Retomando las perspectivas feministas, como sostiene Cavarero (1997), las mujeres han sido históricamente privadas de representarse en su particularidad y unicidad, siendo pensadas siempre desde una tradición que reconoce solamente al sexo masculino como abstracto universal del ser humano. De ahí la importancia de una narrativa desde una perspectiva feminista, desde la cual puedan generarse transgresiones a la voz convencional masculina, y hacer emerger identidades propias, individuales y a la vez colectivas de las mujeres:

Las historias de mujeres (...) les permiten a ellas deconstruir un punto de vista del mundo que pretende ser neutral pero en realidad se corresponde en gran medida con los deseos y necesidades masculinos, aprender a narrarse a sí mismas como mujeres significa legitimar una definición propia por fuera de la mirada del otro (Cavarero, 1997: 60). ${ }^{4}$

4 Traducción propia.
Por último, también Collin (2006) recupera la importancia de incluir las narraciones de las mujeres de un modo amplio, incluyendo tanto los conceptos de historia oral, historias de vidas o incluso de la obra de arte, como formas posibles de inscribir lo general en lo singular, lo político en lo privado. El intento es el de hacer asomar a la experiencia ${ }^{5}$ como una totalidad que excede y trasciende la tradicional visión dualizante de los sexos y de la vida.

Así, las entrevistas de las cuales se desprenden estos desarrollos han sido pensadas entre el formato de preguntas abiertas y la técnica de relatos de vida, tomando la perspectiva de Wacheux (1996): una forma particular en la cual el investigador propone al sujeto estudiado que cuente toda o una parte de su experiencia vivida, procurando limitar al máximo sus intervenciones. Por otro lado, las técnicas de relatos biográficos o de historias de vida tienen otras reglas de procedimiento más vastas y precisas que no han formado parte de nuestro enfoque (Pujadas, $1992,2000){ }^{6}$

En otros términos, si bien nuestro abordaje se aproxima más a las entrevistas en profundidad (Atkinson, 1998) que al de historia de vida, hemos incorporado algunas de las elaboraciones teóricas

$5 \mathrm{El}$ resaltado es propio, la autora si bien utiliza el término no lo utiliza como categoría central en forma explícita. 6 Pujadas, por ejemplo, retoma las reglas de Poirier et al. (1983) para la entrevista de orientación biográfica y a su vez distingue entre "relato biográfico" (life story) entendido como el registro literal de las sesiones de entrevista que el etnógrafo realiza con el entrevistado en las que narra su trayectoria de vida durante varios encuentros, y la "historia de vida" (life history) como un relato también extenso y complejo, pero ya editado y tal como llega a las manos del lector. Mientras, otros autores se han referido a "trayectorias" para identificar transiciones específicas ocurridas en la vida de una persona sin necesidad de incluir la totalidad de su existencia (Thompson, 1988). 
provenientes del uso de estas metodologías, que están en sintonía con la línea de pensamiento feminista. Por ejemplo, varios autores que han utilizado variantes del método biográfico han destacado su importancia para el estudio de la significación atribuida por los sujetos a las vivencias personales. También se ha resaltado la riqueza de la información que puede obtenerse incorporando el carácter retrospectivo, longitudinal y subjetivo de los relatos personales (Sanz Hernández, 2005). Cornejo (2006), por ejemplo, ha señalado que este enfoque "hace accesible lo particular, lo marginal, las rupturas, los intersticios y los equívocos que son elementos clave de la realidad social y sobre todo que explican por qué no hay sólo reproducción" (Cornejo, 2006: 103).

Para finalizar, también desde estas corrientes metodológicas y a modo de alerta, tomamos en consideración que los relatos orales no reflejan hechos sociales "en sí", sino que los sucesos pasados se organizan a partir de la percepción actual de los propios sujetos, imponiéndose una determinada lógica que les otorga un sentido particular (Pujadas, 2000). La experiencia y las narraciones son de naturaleza necesariamente discursiva y - lejos de corresponderse a una "verdad" interna o externaestán atravesadas por representaciones sociales e históricas (Scott, 1993).

\section{INCORPORACIÓN DE NIÑOS Y NIÑAS}

\section{A FAMILIAS ADOPTIVAS \\ EN EL CONTEXTO ARGENTINO ACTUAL}

En el período en que hemos desarrollado nuestra investigación, hemos observado que el Estado argentino ha estado atravesando una transición burocrática, legal y moral en cuanto a las adopciones, que se orienta hacia la protección de los Derechos del Niño y promueve la preservación de la convivencia en su grupo familiar de origen. A partir de estas nuevas lógicas, la adopción es pensada como "solución de último recurso" y se prescribe la obligatoriedad de dar a conocer al adoptado su "verdad".

De esta manera, el reconocimiento del "pasado" (sic.) de los adoptados se impulsa desde varias normativas y prácticas estatales que en su conjunto señalan un direccionamiento en favor de lo que se denominan "orígenes biológicos". Además, en el mismo sentido, ha comenzado a visibilizarse la problemática socio-económica que da forma a las adopciones, provocando una circulación de niños (Fonseca, 1998) desde los hogares de los sectores más marginados hacia las clases medias (Tarducci, 2011).

De forma resumida, podemos afirmar que desde el lenguaje del Interés Superior de Niño se ha impuesto globalmente el derecho a "conocer a sus padres y ser criado por ellos" y a conservar la identidad, incluidos el "nombre, nacionalidad y relaciones familiares". ${ }^{7}$ No obstante, a esto se han agregado en la coyuntura local connotaciones ligadas a un proceso de reformulación de las actuaciones estatales respecto a prácticas previas - especialmente a la luz de las apropiaciones de niños y niñas ocurridas durante la última dictadura militar (Villalta, 2006). En este contexto, se ha incorporado la perspectiva de los organismos de

7 Convención de los Derechos del Niño (CDN). Art. 7 "Nombre y Nacionalidad" y Art. 8 "Preservación de la Identidad". 
Derechos Humanos, principalmente de Abuelas de Plaza de Mayo, que han introducido conceptos como el de identidad biológica y destacan la centralidad de los orígenes (Regueiro, 2009).

De este modo, en el marco de nuestra investigación, nos hemos dedicado, por un lado, a indagar en el conjunto de cambios burocráticos y legislativos que han tenido lugar durante los últimos años en la Argentina y, por otro lado, a explorar de qué modo las familias adoptivas acompañan, resisten o intentan adecuarse a estas transformaciones.

En este contexto, uno de nuestros desarrollos ha consistido en observar que muchas familias adoptivas - entre otros actores relacionados a la adopción - se han movilizado en la esfera pública a partir de la novedosa posibilidad que suponen estas modificaciones para repensar el lugar asignado a las familias de origen (a veces denominadas “biológicas") de los adoptados. En muchas oportunidades, organizadas como "asociaciones virtuales de familias adoptivas", han conformado un actor colectivo que ha ejercido presión en contra de las transformaciones legales.

Sin embargo, al mismo tiempo conocen que como postulantes a adopción y durante un tiempo posterior son evaluados por estas autoridades, y por lo tanto procuran adecuarse a los valores impartidos estatalmente. Asimismo, dado que este conjunto de discursos estatales han conformado un conjunto de nuevos valores legítimos, intentan ser o son acompañados por parte de la amplia mayoría de las familias que han adoptado o deciden adoptar.

En función de esto, a partir de nuestro trabajo con familias conformadas por matrimonios heterosexuales que adoptan niños/as, venimos sosteniendo que los sentidos más recurrentes tienden a reforzar la noción tradicional de pertenencia exclusiva del adoptado al nuevo grupo de parentesco. Por lo general, en nuestro contexto, los nuevos valores morales que promueven el reconocimiento de los vínculos familiares del "pasado" (sic.) y la idea de verdad son integrados de formas que no cuestionen radicalmente el modelo tradicional de pensar las adopciones (Pena, 2015a). ${ }^{8}$

También mediante el análisis de sus relatos, hemos desarrollado las maneras en las cuales mediante ideas que resaltan la emotividad de los momentos de encuentro con el hijo o hija adoptiva, se construyen narraciones que solidifican y legitiman las nuevas conexiones. En este punto es que nuestro estudio recupera y se enmarca en la línea de estudios feministas y de parentesco que proponen que el parentesco o relatedness se conforma a partir de saberes, prácticas, sustancias, lazos de consanguinidad y afectos, entre otras cuestiones, de manera mucho más compleja y abarcativa de lo que los esquemas formalistas podrían dar cuenta (Carsten, 2000; Strathern, 1992).

En función de ello, han sido centrales las elaboraciones de estudios similares con familias adoptivas europeas, que ya han señalado los procesos de creación de "conexiones inmediatas" y de "semejanza imaginada" como elementos clave que contribuyen a crear la idea de pertenencia a la nueva familia (Howell y Marre, 2006).

En el siguiente apartado nos dedicaremos a complementar estas elaboraciones previas a través

8 Para ampliar sobre este asunto, véase el artículo citado y otros trabajos anteriores de esta autora, por ejemplo, Pena (2012, 2014, 2015b). 
de su contrastación con lo observado entre mujeres que han creado familias monoparentales.

ADOPCIONES DISTINTAS: ALTERNATIVAS, CONTINUIDADES Y POTENCIALIDADES EN ALGUNAS FAMILIAS “MONOPARENTALES”

Como venimos desarrollando, durante nuestro trabajo de campo nos entrevistamos extensamente con varias mujeres que han adoptado como mujeres "solteras" "9 (sic.), lo cual es una posibilidad bastante usual. Estas familias, denominadas monoparentales, la mayoría de las veces han respondido a los interrogantes que desarrollamos anteriormente con construcciones similares a aquellas de los matrimonios. Los relatos de semejanza o predestinación y las ideas de una conexión inmediata entre las madres y los hijos adoptados se han presentado con la misma frecuencia que entre las parejas casadas. Asimismo, muchas veces los sentidos en torno a los orígenes también suelen responder a los valores culturales dominantes y coinciden con aquellos propios de las parejas que procuran respetar la verdad y la identidad de los adoptados, pero no desafían el modelo de sustitución de familias.

Siendo que estas mujeres provienen del mismo entorno social y cultural, y que atraviesan los mismos procesos legales y burocráticos que las personas casadas, no hay razones particulares para que en estas cuestiones se presenten diferencias sustanciales. Este punto también se ve reforzado al considerar la maternidad en cuanto práctica histórica y culturalmente determinada, y como

9 Si bien suele denominárselas como "solteras" o "solas", señalando a la ausencia de una pareja masculina, no siempre es éste su estado civil formal, ni tampoco consideramos desde nuestra perspectiva que sea relevante destacar dicha condición. una de las exigencias principales asignadas a las mujeres de acuerdo a su rol de género, tal como ha evidenciado el pensamiento feminista (Knibiehler, 1997; Hays, 1998). Por lo tanto, estos lazos están siempre construidos en diálogo con el ideario que prescribe que el amor y el cariño son vitales y naturalmente propios de las madres (Badinter, 1981; Schepper-Hughes, 1997); y es desde allí en donde se inscribe la heterogeneidad de modos de resolver creativamente las diferentes experiencias particulares.

Estas observaciones nos permiten sugerir que respecto a las preguntas que desarrollamos en este artículo, las adopciones monoparentales no conforman en sí mismas construcciones completamente alternativas o distanciadas de los valores e ideales prevalecientes. Así, no procuramos en esta parte abordar a este tipo de conformaciones de forma totalmente separada al resto de las familias adoptivas, sino reflexionar en torno a ciertas particularidades.

Por otra parte, estudios previos con familias monoparentales y no heteronormativas en contextos similares también han arrojado resultados en relación con las rupturas y continuidades en los nuevos tipos de conformaciones familiares.

Actualmente, las familias contemporáneas se caracterizan por la pluralidad de modelos y estructuras, así como son producto de un conjunto de cambios socioculturales (el acceso de la mujer a la educación, el control de la fecundidad y los procesos de urbanización) que han generado una ruptura del papel que por tradición se les asignaba a la mujer y la familia en la sociedad. También es destacable recordar que, como han apuntado Ariza y 
de Oliveira (2001), "desde los años sesenta diversos movimientos feministas han contribuido a socavar la legitimidad de los roles familiares tradicionales, dando paso a la concepción de la mujer como ser autónomo con capacidad para forjarse un destino propio" (Ariza y de Oliveira, 2001: 16).

Sin embargo, estos mismos estudios nos han alertado contra la tendencia a planteamientos que relacionan los cambios vertiginosos que ha tenido la familia tradicional, con su decadencia o "fin" (Díaz Uribe, 2007). Por el contrario, ha sido señalado con qué asiduidad los estereotipos vinculados a los repertorios maternos y familiares encuentran asidero en relatos de familias conformadas en estructuras alternativas (Libson, 2012). De este modo, en este trabajo seguimos en esta línea de intereses teóricos que se preguntan por los procesos ambivalentes y conflictivos que atraviesan las y los sujetos, antes que preocuparse por la elaboración de modelos polarizados de familias "tradicionales" y "alternativas".

En nuestro contexto nos hemos encontrado con la particularidad de que es más probable que las mujeres "solteras" adopten niños o niñas de mayor edad, quienes por lo general suelen recordar a sus familiares de origen. Creemos que esto plantea -en algunos casos - situaciones especiales que permiten pensar estos vínculos desde otra perspectiva. Obviamente, esta condición puede darse - $\mathrm{y}$ de hecho también la hemos observado - en casos de parejas casadas. Pero nos interesa dejar esbozada la realidad de que actualmente ocurre con más regularidad en situaciones de mujeres que deciden adoptar solas.

El hecho de que a las mujeres que se inscriben como monoparentales se les asignen en adopción niños o adolescentes de mayor edad, o que se privilegie a los matrimonios para los niños pequeños y en mejor estado de salud, es un dato que reconstruimos a través de diferentes fuentes, aunque por supuesto no se manifiesta explícitamente. No obstante, incluso las mujeres que se inscriben usualmente están al tanto de esta situación, y también se da a conocer desde los denominados "equipos" de psicólogas y asesores, que suelen indicarles como recomendación que acepten niños mayores para tener "más posibilidades". Además, esta información ha sido reiterada durante el trabajo de entrevistas a autoridades de distintas instituciones, que por lo general suelen expresar que "lamentablemente todos sabemos que esto es así". En palabras de algunas madres adoptivas que entrevistamos:

Lucila (L): Yo puse lo que a una le sugieren, que es una nena de 3 a 5 años, y después está que en un caso de adopción monoparental, salvo en un caso excepcional que escuché, por derecha, sos un ciudadano de tercera. Antropóloga (A): ¿Cómo fue que llegaste a esa idea? L: Y una lo descubre después, cuando te dicen un bebé no vas a tener, pero yo esa renuncia la había hecho antes igual, en la primera charla del equipo para padres en espera (Entrevista a Lucila, un hijo adoptado a los 9 años).

Cecilia (C): En mi caso el tema era que el chico había sido devuelto por el matrimonio anterior, y era grande, ¿quién lo adopta? Es horrible porque te plantean como que los chicos son de descarte y vos sos de descarte, es horrible, horrible. Lo único que falta es que te revisen la bombacha, todo te revisan. En cambio, un matrimonio, aunque sean grandes, y no estén en condiciones de adoptar, pero tienen dinero... A mí me pidieron un cuarto separado, y a este matrimonio no, vos fíjate 
[...] Te lo hace sentir el juzgado, jel juzgado! Yo me entrevisté con el juzgado, no sólo con la secretaria, con una de las del cargo máximo, no me acuerdo los cargos, y me dijo que me daban al chico porque no había ningún matrimonio que se lo pudiera llevar.

A: ¿Esto te lo dijeron explícitamente?

C: Absolutamente, absolutamente, no había ninguno en carpeta, y como se le pasaba la edad, te lo iban a dar, iban a hacer los informes, psicológicos, etcétera: "de acá a un año te viene, todos los informes", me dijo. Es claro, especialmente todo lo que es el noroeste: Salta, Jujuy, Catamarca no, bueno, el noroeste, son católicos: van a privilegiar matrimonios y no mujeres solas. En cambio, el noreste, Chaco, Formosa, Misiones, me dijo un juez que eran mucho más flexibles con las adopciones monoparentales, yo me entrevisté con un juez y me dijo: "andá directamente" (Entrevista a Cecilia, un hijo adoptado a los 11 años).

\section{Así, nuestro objetivo ahora no es señalar este} tipo de trayectorias individuales como oposiciones al modelo presentado antes. Procuramos, en cambio, iluminar el interrogante en torno a las posibilidades de pensar los lazos familiares y afectivos de origen a partir de estas circunstancias evidenciadas, que sí trazan ciertas alternativas.

De las entrevistas realizadas elegimos dedicarnos en profundidad a dos casos puntuales, para poder ejemplificar y dar cuenta detalladamente de algunas singularidades de las familias monoparentales que hallamos de manera recurrente.

\section{i. Betiana}

En el caso de Betiana, una mujer de 51 años y de sector socio-económico similar a las mujeres que adoptan estando casadas, las motivaciones han sido diferentes a la infertilidad involuntaria, y coinciden con las expresadas por otras mujeres que han elegido esta opción. Las razones manifestadas con mayor frecuencia, en nuestro caso, han tenido que ver con un deseo personal de ser madres independientemente del proyecto de una pareja estable, un anhelo que muchas veces estaba presente pero no se había concretado y otras veces había sido relegado.

De acuerdo con nuestra entrevistada:

Antropóloga (A): ¿Cómo surge para vos la posibilidad de adoptar?

Betiana (B): Hay distintas etapas, te puedo hablar de una etapa de piba, como a los 25 años, que en una situación en la que estuve muy cerca de la maternidad me di cuenta de que no estaba en condiciones psíquicas para ser madre en ese momento, en situaciones de pareja, ¿no? Como que estaba cerca la posibilidad y yo me daba cuenta de que yo no estaba en condiciones. Siete años después estuve como muy cerca de la posibilidad de ser mamá, no era algo concreto, pero bueno, con una pareja, y después no se dio, la pareja fue fallida, y eso hizo que me deprimiera, yo ya me consideraba en condiciones, que estaba madura y con ganas. Y después, bueno, andaba con la idea dando vueltas y no se concretaba, entre los 32 y los 39, y empieza a correr el reloj biológico, el famoso reloj biológico existe. Pero me di cuenta de que por mi perfil, no me daba para tener un hijo si la otra persona no quería, no me daba, por mi historia familiar, ni mejor ni peor que otra, pero por procesos internos que yo viví. Y surgió hablando con una amiga la idea de que si no se daba, en tal caso yo iba a adoptar, pero mucho antes de los 40 .

A: Estaba clara la idea de la maternidad.

B: Sí, la maternidad la tenía clara, lo que tenía claro es que si no lograba armar, entre comillas, una familia armónica ideal, este modelo de familia tradicional que uno tiene metido en la cabeza, no iba 
a tener un hijo por izquierda, ${ }^{10}$ y si no, iba a adoptar, eso sí me surgió claro, no sé cómo pero lo tenía claro. Después, a partir de los 40 empezó todo el proceso más compulsivo de búsqueda, inclusive esta cosa compulsiva de mirar en una pareja que tuviera ganas, de conversar y que por ahí la otra persona me decía: "no, mirá..." Entonces frente a esa posibilidad de que el otro no quisiera yo prefería adoptar.

En estos casos, las trayectorias suelen ser diferentes también porque estas mujeres en muchas ocasiones no han realizado tratamientos de fertilización asistida, por elección propia:

B: Hablé con un médico y me dijo: “Acá hay bancos de esperma" y me negué rotundamente. El tema es que no me daba la cabeza. Yo no sé qué les dicen las actrices [se refiere a casos de difusión mediática sobre actrices públicamente conocidas que han acudido a tratamientos de reproducción asistida], no tengo idea, pero yo sentía que no me daba la cabeza para eso: ni para tener un hijo por izquierda, ni fabricado digamos.

Sin embargo, también está muy presente, en algunos casos como éste, lo que a veces se considera como renuncia o "duelo" frente a la maternidad mediante la reproducción biológica. Estos sentidos guardan relación con los mismos ideales en torno a la familia que describimos en el apartado anterior,

10 Con esta expresión la entrevistada hace referencia a los procedimientos que en Argentina se conocen como "adopciones directas", las cuales consisten en transferencias de niños/as acordadas entre particulares (o a través de intermediarios) y luego refrendadas por un/a juez. Si bien este tipo de circulación de niños no estaba regulado en la Ley Nacional de Adopciones hasta su reforma en 2012, que ahora lo circunscribe a casos excepcionales, ya era considerado moralmente ilegítimo por las autoridades estatales, quienes procuraban desalentarlos (véase Pena, 2014). entrelazados con deseos personales y con presiones sociales:

B: Pasaron muchos [años] desde 'la idea', te decía, a los 37 yo lo venía charlando con una amiga "si no tengo un hijo biológico voy a adoptar", son cosas que uno dice, pero de ahí a hacer el proceso... Yo, en el medio, buscaba una pareja que quisiera tener hijos ¿entendés? Es difícil; a ver: me corría el reloj biológico, desarmar el modelo de familia tradicional, yo pensé en la posibilidad de la adopción, era una idea, de ahí a concretarlo pasaron nueve o diez años, ¡son muchos años!

Desde que estas mujeres comienzan los trámites para adoptar, muchas veces asistiendo simultáneamente a grupos de acompañamiento (Pena, 2015b), a las problemáticas típicas de la adopción se suman otras que les otorgan a estos casos ciertas particularidades. Una de ellas, tiene que ver con afrontar el hecho de que no son consideradas familias "ideales" para adoptar bebés o niños pequeños. Este ejemplo que trabajamos es tan sólo una de las múltiples formas en que se expresan las tensiones entre las intenciones de distanciarse de estas nociones dominantes en torno a la familia, y a la vez procurar adecuarse a ellas:

A: ¿Y esto que decís de que privilegian a los matrimonios? ¿Cómo fue para vos? ¿O cómo lo pensás ahora?

B: A mí me agarró una indignación social, como te dije. A: ¿Vos no lo pensaste como ellos, en términos de desventajas para el hijo?

B: No, para mí fue una indignación social, porque digo, sí, estaría bueno hoy tener una pareja, que realmente sea pareja, pensando por Tomás [su hijo adoptivo], porque Tomás necesita un papá, una figura masculina, pero bueno, hay un lugar en que a mí me preocupa la crianza, en este momento ese lugar lo 
cubren mi hermano y mi papá, y el psicólogo, sus profesores; no descarto la posibilidad de un marido, pero no como ellos lo plantean.

También en respuesta a estas presiones, sociales y jurídicas, las madres adoptivas monoparentales disputan y negocian valoraciones en relación con su aptitud como familias, por una parte en sus actitudes hacia las autoridades, y por otra construyendo sentidos alternativos para sí mismas y su entorno cercano:

A: Te preguntaba, ellos ${ }^{11}$ te ubican en un cierto lugar, según lo que vos decías que sentís, y habrá que pararse frente a eso de alguna manera.

B: Por supuesto, sabés cómo, yo soy profesional, creo que lo estoy criando bien, del colegio nos envían unos informes maravillosos. Y ellos sienten que después de haber fracasado, porque para ellos lo del matrimonio anterior fue un fracaso, en cambio yo fui una semana al hogar, estuve una semana con visitas. Yo tuve otra actitud, porque al matrimonio ni lo conocían, van y se los llevan, yo creo que les mostré otra apertura [haciendo referencia a un matrimonio al cual las autoridades habían adjudicado previamente la adopción de su hijo, la cual había fracasado y el niño había sido "devuelto"].

A: Es interesante hayas cuestionado esta idea que decís que tienen de que siempre es mejor el matrimonio sea como sea.

B: Eso es lo que circula, hasta en el diario, por otro lado yo le decía a otra madre que adoptó siendo soltera, hoy en día la mayoría de las mujeres crían a sus hijos solas, porque están separadas o porque en el día a día están solas, no importa si es adoptivo o no.

11 En la conversación, la entrevistada venía mencionando como "ellos", de manera general, a las diferentes autoridades con las cuales ha debido interactuar durante el proceso de adopción.
En este sentido, quizás una de las diferencias más destacadas con respecto a los matrimonios, es, como adelantamos, el hecho de afrontar la posibilidad de adoptar "niños mayores". Estas realidades, como sugerimos antes, provocan coyunturas a veces más proclives a pensar el asunto de las relaciones afectivas previas $\mathrm{o}$ respecto de sus orígenes desde otra perspectiva. De este modo, en muchas oportunidades aparece el reconocimiento de que dichos vínculos no son simplemente biológicos, sino que han formado parte de la vida y la subjetividad del niño o niña. Además, las biografías y las personas que han significado afectos para los niños pueden ser representadas, como en este caso, mediante relatos más complejos y más humanizados que aquellos que son más frecuentes en adoptantes de bebés o niños muy pequeños:

B: En este caso no era que la madre renunció a la patria potestad, sino que los chicos renunciaron a ella. Es una historia bastante pesadita, como todas, dramática. La mamá de Tomás tiene tres hermanitos, la hermana mayor, Tomás y el hermanito menor, está sola con estos tres chicos y se junta con un hombre que trabaja pero que "chupa", y les pega. Sí, una violencia descomunal. Después, ella vuelve a quedar embarazada de este padrastro y en el momento en que ella iba a tener familia de este hombre, creo que la segunda vez, los lleva a un hogar, los deja en el hogar durante el año. Y yo creo, que dejándolos ahí les salvó la vida, la mina en realidad no es que los abandonó, sino que los lleva a un lugar que les dieran de comer, que los cuidaran, que no les pegaran, claro. Entonces ella los lleva al hogar, en estado de desnutrición los tres, Tomás era el que estaba peor, allí empiezan a ir a la escuela, no les pegaban, y bueno, a fin de año ella quiere volver con ellos, y la 
hermana mayor de Tomás, dice que no, que no quiere volver porque ella continúa con el padrastro.

A: ¿Cuántos años tiene la hermana?

B: Nueve años, pero era como la mamá de los hermanitos, y ellos ya se habían escapado, los había amenazado el padrastro. Bueno, cuando la hermanita dice esto, ahí el juzgado directamente le quita la patria potestad a la madre, no sé cómo fue, si le avisan...

Por otro lado, el privilegio por bebés o niños pequeños puede aparecer planteado con algunas divergencias frente a los sentidos expuestos por las mujeres casadas o las parejas. Las mujeres que entrevistamos han expresado frecuentemente que esta realidad no las perjudicaba demasiado porque coincidía con razones personales para preferir la adopción de un niño mayor, trayendo a colación cuestiones de la "energía" y tiempos requeridos para la crianza. También han considerado la diferencia de edad entre madre e hijo, haciendo referencia a que con los años que tenían en el momento de adoptar "no podría haber sido su madre biológica":

B: Yo sabía de entrada que a una mujer sola, bebés no le daban, y en parte yo prefería, por un lado porque tenía miedo de que sea un bebé con problemas, y en parte porque veía que iba pasando el tiempo, y lo que sentía es que a mí no me daba el cuero para criar un bebé, yo prefería que sea grande; por otro lado, con la gente que conversaba me decía: "mejor que no sea grande". Yo igual la verdad es que cuando me enteré de que era más grande de lo que creía, y que era un varón en lugar de ser una nena, dije: "pero yo siempre quise que sea más grande y prefiero que sea varón, por la composición familiar, porque ya tengo una sobrina".
A: ¿No te molestaba no haber estado cuando era bebé?

B: No, por lo de mi sobrina, y además tenía muy claro el paso del tiempo en mí, yo no quería ser muy grande en relación a él, es como si él hubiera nacido cuando yo tenía 40 ; yo tengo 51 y el 11 . Un día, al poco tiempo me puse a correr detrás de él, jugando, me lastimé una pierna y estuve un año para recuperarme.

Sin embargo, estas diferencias no significan que estos sentidos y procesos sean opuestos a aquellos de los matrimonios. Sugerimos que las respuestas y valoraciones en torno a la noción de orígenes pueden ser en algunos casos más flexibles, dadas las mayores posibilidades de que los niños o niñas recuerden a sus madres y familias y hablen sobre ellos:

B: A veces me angustio y digo: "uh, y la historia con la madre". Por momentos él quiere ir a verlos, y el psicólogo dice que no es bueno para él, y yo entro en contradicciones.

A: ¿Él quiere verlos?

B: Sí, pero también me lo han dicho, no es bueno para él. Yo no le dije que no, que más adelante, que no es bueno, que tiene que estar fortalecido, y además que su historia es muy dura.

A: ¿Y con los hermanitos se sigue tratando?

B: Con las hermanas de acá se ven, los hermanitos que están en su provincia tienen que ver con el padrastro, son hijos de él, las de acá que son de la mamá y de un padre que no sabemos. Es más complejo el vínculo con la madre, no llegan a darle la vuelta bien, pero claramente están en general mucho mejor de lo que estaban allá.

A: ¿Te preocupa el vínculo tuyo con esa posible familia?

B: No, no, para que no hubiera ninguna cosa que se 
supusiera que yo estuviera en alguna "tramoya", yo quise todo legal y transparente. [Las cursivas son propias]

A: ¿Pero te importaría conocer a la madre?

B: No, pasaba más por que no hubiera nada "turbio", pero con el tema de la madre [piensa] pasa que como los vínculos están rotos, y esto es lo que te obliga el juzgado, una no puede conocerlos, y se hace fantasías en torno a la persona. Yo lo que puedo ver es en torno a la afectividad de él, ahora me parece que a mí también me resultó más cómodo que fuera una situación distante, porque era un chico de otro lugar. [Las cursivas son propias]

A: Claro, ¿y pensaste alguna vez en conocerla, te da curiosidad?

B: No sé si curiosidad, no es un tema de curiosidad, me da mucha congoja el sufrimiento de él.

A: ¿Bronca hacia ella?

B: No, porque creo que es lo que pudo hacer, no es lo que piensa el psicólogo, yo creo que ella los protegió al dejarlos en el hogar, los protegió frente al padrastro, y yo creo que hay una determinación tan grande en su situación. Me da mucha pena.

A: ¿Y te preocupa que él quiera volver a verla?

B: No, ¡el primer año él se quería volver! Y yo le dije, pero Tomás, tu mamá está con tu padrastro, vos no podés volver con ella, vas a tener que volver al hogar, porque además él no quería que el padrastro estuviera, digo, había una situación muy complicada en ese sentido, con el padrastro, porque me parece que el padrastro lo que generó fue una situación de expulsión de los hijos que no eran de él, una cosa muy jodida. Un tipo muy muy violento.

Como sostiene Betiana, "en torno a la afectividad" de los niños y niñas mayores, en los casos en los que existe un cierto lazo con algún familiar - cuando no es causa de vulneración de derechos - emergen otras versiones sobre los orígenes, a los que las madres adoptivas dan respuesta de maneras heterogéneas. Algunas veces más sujetas al modelo tradicional de sustitución de familias, y otras tantas permitiendo algunas reflexiones alternativas. En el caso que venimos analizando, si bien no podemos decir que este discurso es contrapuesto al predominante, deja algunas grietas abiertas a otras posibilidades:

B: También me da algo de temor, pero quizás hasta me parece que en algún momento sería bueno para él que se pueda desarmar el fantasma, que la mamá está bien, que los hermanos están bien, porque él tiene miedo de que el padrastro los mate. Yo sé que están vivos, qué están bien, o no sé si bien, “están”. A mí me parece que estaría bueno para él, si él estuviera en mejores condiciones, que los vea, quizás tiene que ser más grande, en este momento si él va creo que puede generarse esa cosa de que me quiero quedar con mi mamá biológica o con vos, esa tensión, esa angustia interna, por ahí puede ser que él lo esté sintiendo también. Y algo que también hablé en un momento con una amiga es sentir el desprendimiento de decir: "Bueno, si él en algún momento quiere ir a vivir con su mamá biológica, estará en todo su derecho también", es algo que él tendrá que ver. [Las cursivas son propias]

A: ¿Reflexionaste sobre eso?

B: Yo le pregunté: "Tomás, ¿vos extrañás?", "Sí”, me dice. Pero yo lo dejo abierto, una vez me dijo: “mamá, ¿por qué no adoptamos a mi hermanito?” y le digo: "tu hermano no está en situación de adopción, tiene papá y mamá", un día que estaba más o menos lúcida. A mí me daba mucho miedo cuando él me decía "me quiero volver", el primer año, pero bueno, "si te querés volver, volvé, yo no te obligo".

\section{ii. Victoria}

Victoria también es una mujer comenzando sus 50 años, profesional y soltera, que ha adoptado 
a una adolescente de 15 años hace cuatro y ha tenido en guarda a su hermana menor de 13 años durante unos meses, hasta que la adolescente decidió retornar con un familiar de origen. De acuerdo con su relato, el proceso de "espera" le resultó particularmente prolongado. La primera vez que realizaron el informe socio-ambiental en su hogar la rechazaron, argumentando, según sus palabras, la falta de una habitación y el hecho de que estaba "sola" y muy dedicada al cuidado de varias mascotas, lo cual interfería en su disponibilidad para la crianza. Unos años más tarde realizó los trámites nuevamente y finalmente fue aceptada. Actualmente se desempeña como una de las integrantes más activas de un grupo virtual restringido solamente a familias monoparentales con la finalidad de "poder hablar de nuestros problemas específicos".

Al igual que en el caso de Betiana y de la mayoría de las mujeres que han adoptado en las mismas circunstancias, en el ejemplo de Victoria se repite la motivación a partir de un deseo muy férreo de convertirse en madre. Asimismo, se reiteran proyectos anteriores de maternidad mediante la procreación biológica, en situaciones de pareja que no han podido llevarse a cabo:

Victoria (V): En mi caso yo quería adoptar desde chica, pensaba que iba a tener hijos biológicos y también adoptados, era algo que pensé siempre, pero estaba ahí nada más. Después, la vida hizo que... bueno, a los 37 años yo tuve una pérdida de embarazo [aborto espontáneo] en una situación muy traumática, con una pareja, una muerte de él [refiere a la pareja] muy traumática. Y no volví a formar pareja ni intentar tener hijos así porque ya era grande. Después quedé un tiempo anestesiada y un día, al tiempo, dije: "voy a adoptar".
También Victoria ha rechazado la posibilidad de hacer uso de tecnologías para la reproducción:

(V): No, no hice tratamientos, no era para mí, pensé directamente en la adopción y empecé a hacer cosas en ese sentido digamos, averiguaciones...

Y nuevamente manifiesta la preferencia personal por un niño o niña "más grande", a la par que conoce que de todas formas sería muy difícil que le asignen bebés o niños muy pequeños:

(V): Yo empecé a pensar, si trabajo mucho no lo puedo cuidar, pero si no, con qué lo mantengo, para ponerlo con una persona que lo cuide todo el día lo dejo donde está. Y además siempre pensé en adoptar un chico más grande porque, primero, decía si yo tengo 49 años no voy a adoptar un bebé porque yo no podría ser su mamá biológica, además de que un bebé no me van a dar [...] Y pensé que podía adoptar a un adolescente, a la psicóloga le dije que quería un chico para darle una familia, podía ser de 14, 15, 16, para acompañarlo a que complete sus estudios, sus proyectos.

Cuando se presentan situaciones de adolescentes en situación de adoptabilidad, como es conocido el hecho de que hay muy pocas familias dispuestas a adoptarlos, los casos se promocionan por diferentes medios y se difunden "pedidos" de postulantes que estén inscriptos en el registro y deseen aceptarlos. Así, Victoria se enteró de la posibilidad de adoptar a quien ahora es su hija a través de un "programa de chimentos" en televisión. Sin embargo, ha afirmado que durante todo el proceso posterior recibió distintas formas de "maltrato" y "discriminación" por ser una mujer soltera, y 
sostiene que los períodos de guarda (legalmente seis meses para matrimonios y diez para familias monoparentales) le han resultado extensos y que se ha sentido "evaluada en todo":

(V): En el caso de C, primero me dieron una guarda para que pase dos meses de vacaciones conmigo, y cuando volvemos le preguntan a ella si quiere volver al hogar o quedarse conmigo, y ella dice que quiere quedarse. Entonces a los varios meses me dieron la guarda preadoptiva, después a los diez meses y un día comienza el juicio de adopción.

La adolescente que finalmente ha adoptado es huérfana de padre y madre, pero tiene una abuela y varios hermanos:

(V): C vivía con su mamá, que había tenido una nena de muy jovencita, y siempre se la dejó a la abuela. Más tarde conoce al papá de los hermanos de $\mathrm{C}$ y se va a vivir con él, un hombre grande que ya tenía otros hijos, era alcohólico y tienen cuatro hijos, C es hija de ellos y [menciona los nombres de los otros hermanos]. Cuando ya estaba embarazada de la nena, la situación, los golpes eran terribles y se separa de él. Ahí conoce al que es el papá de [nombres], medios hermanos de $\mathrm{C}$ con otro hombre, y en algún momento, se ve que estuvo con otra persona, se contagia la mamá de VIH, pero los chicos están bien, no tienen el virus. Y bueno, ella lo contagia a él, según los chicos. Él representa para los chicos una figura muy querida, es quien les dio cariño, no sólo a sus hijos sino a todos los chicos de ella. $\mathrm{C}$ dice que la ayudaba con las cosas de la escuela, lo quieren, es decir; cuando él muere, $\mathrm{C}$ intentó suicidarse, sentía mucho apego [...] Y bueno, cuando este hombre muere, la mamá —que está enferma- queda internada y los chicos quedan todos con la abuela, también con los chicos de parte del papá y [nombre] que es un embarazo de la mamá con otro chico de 18 años. Porque la familia del papá no vive ahí, vive lejos. Y ni la abuela ni $\mathrm{C}$ quieren saber nada ni con la familia del papá ni con la del papá de los hermanos [...] Un día la abuela agarró a los cuatro mayores, ellos eran siete, les dijo que tenían un cumpleaños, llamó un remis ${ }^{12}$ y se fue. Le dijo al remis que deje a las chicas en un hogar. Pero C se escapó y estuvo perdida hasta que la encontró la policía, después volvió un tiempo con la abuela, que después la dejó de nuevo en un hogar, y ahí la conocí yo, cuatro años después. Esto fue cuando ella tenía 11 años.

Con respecto a esta realidad de que su hija adoptiva tiene vínculos familiares y afectivos previos, y que es algo más probable al adoptar niños mayores o adolescentes, Victoria confiesa que lo había pensado antes de adoptar "pero no demasiado". Su perspectiva cambió y según sus palabras "cayó en la cuenta", a partir de conocer a su hija y a las circunstancias concretas que forman parte de su vida. Diferentes cuestiones fueron mostrando la importancia de las relaciones afectivas de $\mathrm{C}$ en el momento actual, y la realidad de que muchas personas, como sus hermanos y abuela, son parte de su subjetividad y para ella “están presentes".

Victoria decidió mantener el contacto con la familia "biológica" - principalmente la abuela y los hermanos que continúan bajo su cuidado, además de otros que están actualmente al cuidado de distintas personas - fomentando visitas mutuas y también integrándose ella misma a este grupo de afectos:

(V): Yo creo que la adopción de chicos grandes es muy difícil. Generalmente tienen vínculos

12 Coche de arrendamiento con un chofer. 
biológicos, yo incluso intenté traer a la más grande de las hermanas a casa, adoptarla, pero ya tiene 19 años y [...] con la abuela y los hermanos, aunque no viven juntos, el vínculo sigue.

\section{CONCLUSIONES}

Este artículo ha sido planteado en continuidad con elaboraciones previas que han sido retomadas, en las que habíamos analizado los sentidos y valores prevalecientes entre las familias adoptivas consideradas como "norma" en el campo nacional de la adopción. Así, hemos partido de la hipótesis de que más allá de modificaciones en torno a la concepción de los orígenes y la verdad, los discursos mayoritarios no se distancian cualitativamente de la idea de filiación exclusiva.

Aquí, hemos planteado un recorrido complementario, en el que indagamos en torno a lo que sucede con las familias denominadas "monoparentales", conformadas por mujeres que deciden adoptar niños, niñas o adolescentes de manera individual, centrándonos en las representaciones y prácticas mediante las cuales se construye su incorporación al nuevo parentesco.

Obviamente, las aristas y formas de abordar estos procesos son múltiples, y hemos elegido focalizar en algunas de las problemáticas que creemos mejor responden a nuestros interrogantes, dejando algunas cuestiones para profundizar en un futuro. Nuestra aproximación se ha preocupado principalmente por los sentidos creados alrededor de la integración a la nueva familia y sus implicancias respecto al lugar asignado a la biología, los orígenes y los lazos afectivos previos. Sin embargo, por ejemplo, no hemos ahondado en las experiencias particulares de cada una de estas mujeres con los aspectos burocráticos, un aspecto que también puede contribuir a ampliar este estudio.

En forma resumida, en este trabajo hemos sugerido la idea de que las adopciones "monoparentales", si bien no representan en sí mismas un modelo alternativo, dadas algunas condiciones - a veces no deseadas - pueden auspiciar construcciones diferentes. La adopción más frecuente de niños/as o adolescentes de mayor edad, o la necesidad de estas madres de separarse de discursos discriminatorios hacia ellas, han propiciado en algunos casos reflexiones más flexibles e inclusivas de las vivencias y afectos de los adoptados.

En función de este planteo, nos ha resultado de gran utilidad haber enmarcado nuestra investigación en la línea de los estudios antropológicos de parentesco y en la tradición feminista. Estas corrientes de pensamiento han desarrollado extensamente conceptos y metodologías que permiten abordar las conexiones familiares como construcciones y procesos creativos y dinámicos que - lejos de estar signados por la "naturaleza" - se desenvuelven de maneras diversas. Dicho conjunto de aportes ha posibilitado un desarrollo a partir de la experiencia de estas mujeres que han construido su maternidad y sus lazos familiares dentro de posibilidades preestablecidas pero a la vez reinventándolos de manera cotidiana. Por último, también hemos procurado recuperar la riqueza de sus matices y contradicciones mediante el uso de sus propios relatos. 2o 


\section{BIBLIOGRAFÍA}

Adán, Carme (2006), Feminismo y Conocimiento. De la experiencia de las mujeres al Ciborg. La Coruña, Spiralia Ensayo.

Ariza, Marina y Orlandina de Oliveira (2001), "Familias en transición y marcos conceptuales en redefinición", en Papeles de Población, vol. 7, núm. 28, pp. 9-39.

Atkinson, Robert (1998), The life story interview. Londres, Sage Publications.

Badinter, Elisabeth (1981), ¿Existe el instinto maternal? Barcelona, Paidós.

Bertaux, Daniel (1999 [1980]), “El enfoque biográfico, su validez metodológica sus potencialidades”, en Proposiciones, núm. 29, pp. 1-22. URL: http://preval.org/files/14BERTAU.pdf

Bestard Camps, Joan (2004), "Kinship and the new genetics. The changing meaning of biogenetic substance", en Social Anthropology, vol. 12, núm. 3, pp. 253-263, DOI: 10.1111/j.1469-8676.2004.tb00107.x

Carsten, Janet (ed.) (2000), Cultures of Relatedness. New approaches to the study of kinship. Cambridge, Cambridge University Press.

Castañeda Salgado, Martha (2008), Metodología de la Investigación Feminista. México, Fundación Guatemala, Centro de Investigaciones Interdisciplinarias en Ciencias y Humanidades, Universidad Nacional Autónoma de México.

Cavarero, Adriana (1997), Relating Narratives. Storytelling and Selfhood. Londres, Routledge.

Collier, Jane, Michelle Z. Rosaldo y Silvia Yanagisako (1982), "Is there a family? New Anthropological Views", en Barrie Thorne y Marilyn Yalom (eds.), Rethinking the Family. Some Feminist Questions. Reino Unido, Longman, pp. 25-39.

Collin, Françoise (2006), Praxis de la diferencia: Liberación y libertad. Barcelona, Icaria Editorial.

Cornejo, Marcela (2006), “El enfoque biográfico: Trayectorias, desarrollos teóricos y perspectivas”, en Psykhe, vol. 15, núm. 1, pp. 96-105. 
Díaz Uribe, Patricia (2007), "Familias monoparentales con jefatura femenina, una de las expresiones de las familias contemporáneas”, en Tendencias \& Retos, núm. 12, pp. 81-90.

Fonow, Margaret y Judith Cook (2005), "Feminist Methodology: New applications in the academy and public policy”, en Signs: Journal of Women in Culture and Society, vol. 30, núm. 40, pp. 2211-2236.

Fonseca, Claudia (1998), Caminos de Adopción. Buenos Aries, Eudeba.

Fonseca, Claudia (2011), "The de-kinning of birthmothers: reflections on maternity and being human", en Vibrant: virtual Brazilian Anthropology, vol. 8, núm. 2, pp. 306-339, DOI: http://dx.doi.org/10.1590/ S1809-43412011000200014

Guber, Rosana (2011), La etnografía. Método, campo y reflexividad. Buenos Aires, Siglo XXI.

Hammersley, Martyn y Paul Atkinson (1994), Etnografia: métodos de investigación. Barcelona, Paidós.

Harding, Sandra y Gloria Elena Bernal (1998), ¿Existe un método feminista?, en Eli Bartra (comp.), Debates en torno a una metodología feminista. México, Universidad Autónoma Metropolitana, pp. 9-34.

Hays, Sharon (1998), Las contradicciones culturales de la maternidad. Barcelona, Paidós.

Howell, Signe y Diana Marre (2006), “To kin a transnationally adopted child in Norway and Spain: The achievement of resemblances and belonging”, en Ethnos, vol. 71, núm. 3, pp. 293-316.

Knibiehler, Yvonne (1997), La révolution maternelle: femmes, maternité, citoyenneté depuis 1945. Paris, Perrin.

Libson, Micaela (2012), "Parentalidades gays y lesbianas: varones y mujeres en familias no heteronormativas", en La Ventana, vol. 4, núm. 35, pp. 292-321.

Menéndez, Eduardo (2002), "El punto de vista del actor: homogeneidad, diferencia e historicidad”, en Menéndez, Eduardo (ed.), La Parte Negada de la Cultura: Relativismo, Diferencias y Racismo. Barcelona, Bellaterra, pp. 291-366.

Modell, Judith (1994), Kinship with strangers: Adoption and Interpretations of Kinship In American 
Culture. California, University of California Press.

Oxman, Claudia (1998), La Entrevista de Investigación en Ciencias Sociales. Buenos Aires, Editorial Universidad de Buenos Aires.

Pena, Mariela (2012), "El proyecto de reforma de la ley de adopción: una perspectiva desde la antropología del parentesco", en Cuestión de Derechos, vol. 3, núm. 2, pp. 32-47.

Pena, Mariela (2014), “'Hacer las cosas bien’. Adopciones, parentesco y maternidad en los nuevos significados morales construidos desde el Estado”, en Mónica Tarducci, (comp.), Feminismo, lesbianismo y maternidad en Argentina. Buenos Aires, Librería de Mujeres Editoras, pp. 133-156.

Pena, Mariela (2015a), "La integración de niños y niñas a familias adoptivas en Argentina, conexiones legítimas", en Revista Latinoamericana de Ciencias Sociales, Niñez y Juventud, en prensa.

Pena, Mariela (2015b), “Los postulantes a adopción: biología, deseos y afectos para definir las fronteras de la familia", en Periferia, vol. 20, núm. 1, pp. 34-55, DOI: http://dx.doi.org/10.5565/rev/periferia.446

Pujadas, Juan José (1992), El método biográfico. El uso de las historias de vida en ciencias sociales. Madrid, Centro de Investigaciones Sociológicas.

Pujadas, Juan José (2000), “El método biográfico y los géneros de la memoria”, en Revista de Antropología Social, núm. 9, pp. 127-158.

Regueiro, Sabina (2009), "Restitución de niños desaparecidos: usos políticos del parentesco en la justicia", en Antropolítica, Revista Contemporânea de Antropologia, núm. 26, pp. 37-62.

Sanz Hernández, Alexia (2005), "El método biográfico en investigación social: potencialidades y limitaciones de las fuentes orales y los documentos personales”, en Ascelpio, vol. 57, núm. 1, pp. 99-115, DOI:10.3989/asclepio.2005.v57.i1.32

Schepper-Hughes, Nancy (1997), La muerte sin llanto: violencia y vida cotidiana en Brasil. Barcelona, Ariel.

Schneider, David (1984), A Critique of the Studies of Kinship. Michigan, The University of Michigan Press. 
Scott, Joan. W (1993), "El género: una categoría útil para el análisis histórico”, en María Cecilia Cangiano y Lindsay DuBois (comps.), De mujer a género: teoría interpretación y practica feminista en las ciencias sociales. Buenos Aires, Centro Editor de América Latina, pp. 17-50.

Strathern, Marilyn (1992), After Nature: english kinship in the late twentieth century. Cambridge, Cambridge University Press.

Tarducci, Mónica (2011), La adopción. Una aproximación desde la antropología del parentesco. Buenos Aires, Librería de Mujeres Editoras.

Thompson, Paul (1989), The voice of the past, oral history. Oxford, Oxford University Press.

Villalta, Carla (2006), "Entregas y secuestros: la apropiación de 'menores’ por parte del Estado", Argentina, Facultad de Filosofía y Letras, Universidad de Buenos Aires, Tesis de Doctorado en Antropología.

Wacheux, Frédéric (1996), Méthodes Qualitatives et Recherche en Gestion. París, Economica.

Fecha de recepción: 24 de marzo de 2016

Fecha de aceptación: 30 de junio de 2016

\section{ACERCA DE LA AUTORA}

\section{MARIELA PENA}

(marielapena6@gmail.com)

Es doctora en antropología por la Facultad de Filosofía y Letras de la Universidad de Buenos Aires y licenciada en ciencias antropológicas por la misma universidad. Ha estudiado temáticas relacionadas con género, religión y parentesco, y ha realizado una investigación etnográfica sobre la adopción en Buenos Aires, de la que elaboró una tesis doctoral. Actualmente se desempeña como investigadora, con sede de trabajo en el Instituto Interdisciplinario de Estudios de Género (IIEGE), de la Facultad de Filosofía y Letras de la Universidad de Buenos Aires. Forma parte de la CAF (Colectiva de Antropólogas Feministas) y del proyecto de investigación UBACyT, "Politizando la vida cotidiana: sexualidad y parentesco en la Argentina contemporánea". Es profesora adjunta en la Universidad de Lomas de Zamora y profesora 
asociada en CEMIC. Ha ejercido otros cargos docentes a nivel universitario y ha formado parte de varios equipos de investigación. Sus áreas de interés son género, familia, sexualidad, infancia y parentesco. 